\title{
Glycemic Control by Umbilical Cord-Derived Mesenchymal Stem Cells Promotes Effects of Fasting-Mimicking Diet on Type 2 Diabetes
}

\section{$\mathrm{Na}$ Zhao}

Xi'an Jiaotong University Second Affiliated Hospital

\section{Ying-Feng Gao}

Xi'an Jiaotong University Second Affiliated Hospital

\section{Lei Bao}

Xi' an No. 4 Hospital

Jing Lei

Xi'an No. 4 hospital

\section{Huan-Xiao An}

Xi'an Jiaotong University Second Affiliated Hospital

\section{Feng-Xing Pu}

Xi'an Jiaotong University Second Affiliated Hospital

\section{Rui-Ping Cheng}

Xi'an Jiaotong University Second Affiliated Hospital

\section{Ji Chen}

Fourth Military Medical University: Air Force Medical University

\section{Hua Ni}

Xi'an Jiaotong University Second Affiliated Hospital

\section{Bing-Dong Sui}

Fourth Military Medical University: Air Force Medical University

Fan-Pu Ji

Xi'an Jiaotong University Second Affiliated Hospital

Cheng-Hu Hu ( $\nabla$ chenghu@xiterm.com )

Xi'an Jiaotong University Second Affiliated Hospital

\section{Research Article}

Keywords: Fasting-mimicking diet, Glycometabolism, Human umbilical cord-derived mesenchymal stem cells, Inflammatory cytokines, Lipometabolism, Type 2 diabetes.

Posted Date: March 5th, 2021 
DOl: https://doi.org/10.21203/rs.3.rs-266022/v1

License: (c) (1) This work is licensed under a Creative Commons Attribution 4.0 International License. Read Full License

Version of Record: A version of this preprint was published at Stem Cell Research \& Therapy on July 13th, 2021. See the published version at https://doi.org/10.1186/s13287-021-02467-7. 


\section{Abstract}

Background Hepatic steatosis is a big hurdle to treat type 2 diabetes (T2D). Fasting-mimicking diet (FMD) has been shown to be an effective intervention in dyslipidemia of T2D. However, fasting might impair the normal glucose metabolism. Human umbilical cord-derived mesenchymal stem cells (UC-MSCs) transplantation has been discovered to regulate immune reactions and reduce hyperglycemia in diabetes. However, the effects of UC-MSCs on improving the lipid metabolism disorder are not quite satisfactory. We have investigated the efficacy comparison and interaction between two typical therapies of FMD and UC-MSC infusion, aiming to pave an avenue for their synergistic use, establish effective T2D therapies and explore its mechanism.

Methods C57/BL6 mice were fed with high-fat diet (HFD) for 16 weeks to induce a diet-induced obese (DIO) mouse model. Six-week-old leptin-receptor-deficient ( $\mathrm{db} / \mathrm{db})$ mice were used for follow-up experiments. DIO or db/db mice were divided into 4 groups: PBS, UC-MSCs $\left(1 * 10^{6}\right)$, FMD (entails 4-day FMD and 7-day of refeeding (RF)) and UC-MSCs + FMD. At the end of the study period, mice were fasted for $6 \mathrm{~h}$ with the measurement of blood glucose and body weight, and then sacrificed. Blood was collected to determine levels of $\mathrm{HbA}_{1 \mathrm{c}}$, serum insulin, and cytokines. In addition, the fresh liver, skin and white adipose tissue were analyzed by histology.

Results FMD restored the lipid metabolism in DIO mice, whereas its capacity to rescue hyperglycemia was uncertain. Infusion of UC-MSCs was effective in T2D glycemic control but the impact on dyslipidemia was insufficient. Furthermore, both the glucose and the lipid alterations of DIO and db/db mice recovered after UC-MSCs combined with FMD. It was proved that UC-MSCs promoted FMD effects on ameliorating hyperglycemia and restoring the lipid metabolism in T2D mice, while FMD had little promotion effect on UC-MSCs. Mechanistically, we discovered that UC-MSC infusion significantly modulated systematic inflammatory microenvironment, which contributed to concerted actions with FMD.

Conclusions We established a strategy that combined UC-MSC infusion and FMD were effective in treating T2D, which synergistically attenuated hyperglycemia and improved the lipid metabolism through immunoregulation. The significance of the work is to provide potential approaches for developing novel clinical T2D therapies.

\section{Introduction}

It is estimated that $\mathbf{4 1 5}$ million people worldwide are currently living with diabetes[1], resulting in plenty of patients with complications in the liver, kidney, the cardiovascular system and so on. Particularly, high-fat diet (HFD) results in the development of obesity which is a major risk factor for T2D [2,3]. Since the liver is a major organ for glucose metabolism, it has become one of the important targets in maintaining the blood glucose homeostasis and in treating T2D. Noteworthy is that almost all patients with T2D display lipid accumulation in the liver causing hepatic steatosis, which represents a big hurdle to cure T2D [4-6]. 
There is also evidence that dyslipidemia can cause insulin resistance, which can greatly reduce the therapeutic effect of T2D[7].

It has been recently reported that caloric restriction induces a specific lipidome and metabolome reprogramming event in the liver with protective effects against dietary lipid excess [8, 9]. Fastingmimicking diet (FMD), a kind of caloric restriction which represents a dietary mode low in calories, sugars, and proteins but high in unsaturated fats, can dramatically reduce triglycerides (TG), total and lowdensity lipoprotein cholesterol, resulting in a loss of total body fat and a reduction of liver fat accumulation [10-12]. Although some studies documented that FMD ameliorated insulin resistance and T2D by inhibiting the inflammatory cytokines such as IL-1 $\beta$, IL-4, IL-6 and TNF- $\alpha$ [13, 14], its capacity of glycemic control may be unstable, sometimes may even cause hypoglycemia Long-term treatment must be performed to achieve the expected therapeutic effects $[10,12,15]$.

Mesenchymal stem cells (MSCs) are a subset of pluripotent stem cells with the capacity of proliferation, differentiation into multiple lineages and immunomodulation/anti-inflammation through their paracrine effects, which makes them promising candidates for translational application [16, 17]. In particular, previous studies have reported that systemic infusion of umbilical cord-derived MSCs (UC-MSCs), as a novel stem-cell-based therapy, regulate immune reactions in diabetes by secreting cytokines, such as prostaglandin E2 ( $\mathrm{PGE}_{2}$ ), nitric oxide (NO), TGF- $\beta$ and hepatic growth factor (HGF), which inhibit proliferation and activation of T cells [18-21]. Moreover, injected UC-MSCs can significantly reduce blood glucose, glycated hemoglobin and the incidence of diabetic complications in T2D patients with high safety and long duration $[22,23]$. Unfortunately, although it is highly valid in controlling blood glucose, the effect on improving lipid metabolism disorder is not quite satisfactory [24].

Here, we aimed to investigate the efficacy comparison between FMD and UC-MSCs in the treatment of T2D in diet-induced obese (DIO) mouse model and discovered that FMD significantly reduced weight gain and improved the lipid metabolism while the effects on regulation of glucose metabolism were uncertain. Despite that therapeutic effects of UC-MSCs on the abnormal lipid metabolism in DIO mice was not good, it significantly ameliorated glucose disposal. These results motivated us to examine the treatment in DIO mice and leptin-receptor-deficient (db/db) mice with the combination of UC-MSCs and FMD. It is revealed that UC-MSCs promoted liver function based on immunoregulation, which further enhanced the effects of FMD on controlling hyperglycemia and lipid metabolism disorders. The results showed great potential for new clinical T2D therapies.

\section{Methods}

\subsection{Animal Model}

Four-week-old male C57/BL6 mice were purchased from Fourth Military Medical University (Xi'an, China) and five-week-old male diabetic $\mathrm{db} / \mathrm{db}$ (BKS.Cg-Dock7 ${ }^{\mathrm{m}}+/+\mathrm{Lepr}^{\mathrm{db}} / \mathrm{J}$ ) mice and non-diabetic $\mathrm{m} / \mathrm{m}$ mice 
as normal group were purchased from Model Animal Research Center of Nanjing University (Nanjing, China). All mice are housed with a $12 \mathrm{~h} / 12 \mathrm{~h}$ light/dark cycle at an ambient temperature of $22-25^{\circ} \mathrm{C}$.

All procedures were performed in accordance with the institutional guidelines for animal care and utilization.

Five-week-old C57/BL6 mice were fed with high-fat diet (HFD, D12492, Research Diets, USA) to induce diet-induced obese (DIO) mouse model for 16 weeks, and mice fed with regular chow diet (RCD) were used as control group.

\subsection{FMD treatment}

The mouse FMD protocol was a 4-day regimen [25]. Each FMD cycle entails 4-day FMD and 7 days of refeeding (RF), which forms 11 days per cycle for 7 cycles. The FMD diet was $50 \%$ of the standard daily calorie intake on day 1 and $10 \%$ of normal daily calorie intake on day 2 to 4 . Prior to supplying the FMD diet, animals were moved into fresh cages to avoid feeding on residual chow and coprophagy. All mice were supplied with wholesome food during the morning hours (8 a.m.-10 a.m.). FMD mice generally consumed the supplied food within the first few hours of the light cycle. Control-fed animals usually consumed the supplied food during the dark hours. All animals had access to water at all time.

\subsection{Cell Culture, Identification and Infusion}

UC-MSCs were isolated using the tissue block culture attachment method [26, 27]. In brief, umbilical cord vein and arteries with their surrounding Wharton jelly were separated from stroma by manual stripping. The mesenchymal tissue in Wharton jelly was minced into cubes of $2-3 \mathrm{~mm}^{3}$ pieces, transferred to petri dishes and cultured in a $37^{\circ} \mathrm{C}$ incubator with $5 \% \mathrm{CO}_{2}$ in a-MEM (Invitrogen, USA) with $10 \% \mathrm{FBS}$ (Gibco, USA). Then medium was changed every 2 days after plating and 10 days later, the tissue blocks were removed. When the cells reached $70-80 \%$ confluence, they were harvested and cultured at a density of $1 \times 10^{4}$ cells $/ \mathrm{cm}^{2}$. The cells in passage 5 were used for experiments.

For the cellular identification, UC-MSCs at passage 5 were gathered to assess surface antigens by flow cytometry analysis on CytoFLEX flow cytometer (Beckman Coulter, Brea, California, USA). UC-MSCs were incubated with the following fluorescent antibodies, all from eBioscience (San Diego, CA, USA): FITClabeled CD14 (11-0149-42), CD19 (11-0199-42), CD73 (11-0739-42), HLA-DR or PE-labeled, CD34 (120349-42), CD45 (12-0459-42), CD90 (12-0909-42), CD105 (12-1057-42), or IgG (12-4714-82).

The DIO or $\mathrm{db} / \mathrm{db}$ mice were randomly divided into four groups ( $\mathrm{n}=6 /$ group): DIO or $\mathrm{db} / \mathrm{db}$, UC-MSCs, FMD, UC-MSCs combined with FMD (UC-MSCs + FMD). UC-MSCs $\left(1 \times 10^{6}\right)$ were suspended in $0.2 \mathrm{ml}$ PBS and injected into mice via the tail vein. The control groups were treated with an infusion of $0.2 \mathrm{ml}$ PBS. The mice were treated with cell therapy for 3 times on day 1 beginning of FMD, 30 and 60 . At day 77, the end of the study period, all mice were fasted for $6 \mathrm{~h}$, blood glucose and body weight were measured, then sacrificed.

\subsection{Blood Glucose Analyses}


The mice were starved for $6 \mathrm{~h}$ before the measurement of blood glucose levels and body weight. Tail venous blood glucose levels were monitored with a gluco-meter ACC-CHEKA performa (Roche, Indianapolis, Indiana, USA). For IPGTT, after $6 \mathrm{~h}$ of fasting, all mice were intraperitoneally injected with 2 $\mathrm{g} / \mathrm{kg}$ glucose and blood glucose was drawn to measure at $0,15,30,60,90$, and 120 min after glucose injection. AUC above baseline was calculated as an index of glucose tolerance.

\subsection{Biochemical and Cytokine Assays}

The levels of $\mathrm{HbA}_{1 \mathrm{c}}$ and $\mathrm{Hb}$ in whole blood were measured by ELISA kits (FanKew, China). The serum was collected after blood was placed at room temperature for $1 \mathrm{~h}$ and centrifuged at $3000 \mathrm{~g}$ for $10 \mathrm{~min}$. The levels of serum insulin, IL-1 $\beta$, IL-6, IL-10, TNF- $a$, IFN- $\gamma$ and TGF- $\beta$ were determined also using ELISA kits (Neobioscience, China). Serum total cholesterol (TC), TG, free fatty acid concentrations (FFA), alanine aminotransferase (ALT), and aspartate transaminase (AST) were measured by chemical test kits (Nanjing Jian Cheng Bioengineer Institute, China). All experimental procedures were performed according to the instructions.

\subsection{Histological Analysis}

The fresh liver, skin and white adipose tissue samples were fixed in $4 \%$ paraformaldehyde, dehydrated by serial alcohol, and embedded in paraffin. Paraffin-embedded sections were stained with H\&E according to the standard protocol. For evaluating lipid accumulation in the liver, samples were frozen embedded in optimal cutting temperature compound (OCT, Leica, Wetzlar, Germany), sliced into $8 \mu \mathrm{m}$ and then stained with $0.5 \%$ Oil Red 0 solution for 30 min at room temperature. Quantification of lipid droplet area, thickness of skin fat layer and adipocyte size used the Image $J$ software (National Institute of Mental Health, USA).

\subsection{Statistical Analysis}

All data are expressed as the mean \pm SD. The data were analyzed using unpaired two tailed Student $t$ tests for two group comparisons. One-way ANOVA follow by Tukey's multiple comparison test was performed for multiple groups comparisons. IPGTT were measured by two-way ANOVA follow by Tukey's multiple comparison test. A value of $P<0.05$ was considered significant. All statistical analyses were performed using Graphpad Prism 7.0 software (GraphPad Software, La Jolla, CA, USA).

\section{Results}

\subsection{Identification of DIO Mice Model and UC-MSCs}

To test the therapeutic effects of UC-MSCs and FMD cycles on T2D, DIO mouse model was induced by 16 weeks of HFD feeding. With HFD feeding, blood glucose levels in DIO mice increased gradually and were significantly higher than the control group from 8 weeks of HFD feeding (Fig. 1a). Then, IPGTT showed noticeable deterioration of glucose disposal in DIO mice (Figure S1a, b). The levels of $\mathrm{HbA}_{1 \mathrm{c}}$ and serum insulin of DIO mice increased markedly (Figure S1c-e). Besides, after 16 weeks of HFD feeding, DIO mice showed significantly increased body weight (Fig. 1b) and the body weight gain was $18 \mathrm{~g}$ more than of the 
control group (Figure S1f). Moreover, the concentrations of serum AST, ALT, TC, TG and FFA were substantially up-regulated in DIO mice, indicating dysregulated lipid metabolism and impaired liver function (Fig. 1C-g). In addition, H\&E and Oil Red O staining of liver indicated severe hepatic steatosis in the DIO mice, shown as the accumulation of lipid droplets in hepatocytes (Fig. 1h, j). Thickened skin fat layer and larger visceral adipocyte size were presented by H\&E staining of skin and visceral fat (Fig. 1i, k, I). These results showed successful establishment of the DIO type 2 diabetic mouse model.

For identification of UC-MSCs, they were be harvested, and the cell phenotypes were detected using flow cytometry. UC-MSCs expressed CD73, CD90 and CD105, and seldom expressed CD14, CD19, CD34, CD45 or HLA-DR, which were consistent with the phenotypical characteristics of MSCs (Fig S2a).

\subsection{UC-MSC Infusion Improved Glucose Homeostasis in DIO mice Better than FMD Cycles}

To investigate the therapeutic effects of UC-MSC infusion and FMD cycles on DIO mice. DIO mice were divided into three groups: DIO, FMD and UC-MSCs $\left(1 \times 10^{6}\right.$ cell/dose in $0.2 \mathrm{~mL}$ PBS) (Fig. 2a). With treatment, fasting blood glucose in FMD $(10.8 \pm 0.36 \mathrm{mmol} / \mathrm{L})$ and UC-MSCs $(7.7 \pm 0.89 \mathrm{mmol} / \mathrm{L})$ group were decreased and lower than DIO group $(13.0 \pm 0.75 \mathrm{mmol} / \mathrm{L})$, but fasting blood glucose in FMD group was still a little high (Fig. 2b). The results of IPGTT showed UC-MSC infusion and FMD cycles could ameliorate glucose disposal with reduced AUC in DIO mice, but UC-MSCs group better than FMD group (Fig. 2c, d). Besides, $\mathrm{HbA}_{1 \mathrm{c}}$ and serum insulin concentration were not markedly changed after receiving 7 FMD cycles, but dramatically declined after UC-MSC infusion (Fig. 2e-g).

\subsection{FMD Cycles Regulated Lipid Metabolism in DIO mice Better than UC-MSC infusion}

Interestingly, H\&E and Oil red O staining showed the FMD cycles markedly reduced the liver steatosis, but only slight alleviation of liver steatosis by UC-MSC infusion (Fig. 3a, b, Figure S3a). Moreover, the skin fatty layer thickness and the visceral adipocyte size were reduced by FMD cycles and no substantially change was observed after UC-MSC infusion, as examined by H\&E (Fig. 3c, d, Figure S3b, c). Furthermore, after receiving 7 FMD cycles, the FMD group showed a significant declination in body weight (45.06 \pm $1.18 \mathrm{~g})$ compared to the DIO mice $(53.96 \pm 3.27 \mathrm{~g})$ (Fig. $3 \mathrm{f})$, together with weight loss $(-0.52 \pm 0.41 \mathrm{~g})$ (Fig. 3e). Body weight in UC-MSCs group (51.72 \pm 2.64$)$ had a lower weight gain $(5.01 \pm 0.28 \mathrm{~g})$ than DIO group $(5.70 \pm 0.41 \mathrm{~g})$ while no significant difference was detected between two group in body weight (Fig. 3e, f). In addition, the concentrations of serum TC, TG, FFA, AST and ALT in DIO mice were suppressed after FMD cycles and UC-MSC infusion and FMD cycles were much better than UC-MSC infusion (Fig. 3g-k). These results demonstrated effective effects of FMD on the lipid metabolism in T2D but uncertain effects on hyperglycemia, and effective glycemic control by UC-MSCs with scarce effects on the lipid metabolism.

\subsection{UC-MSC Infusion Combined with FMD Improved Glucose Homeostasis as UC-MSC infusion}

To evaluate whether UC-MSCs combined with FMD can further improve glucose homeostasis in DIO mice. By comparing the fasting blood glucose levels of DIO mice treated with FMD, UC-MSCs $\left(1 \times 10^{6}\right.$ cell/dose in $0.2 \mathrm{~mL}$ PBS) and UC-MSCs combined with FMD (Fig. 4a). We found that fasting blood glucose in UC-MSCs combined with FMD group $(7.7 \pm 0.60 \mathrm{mmol} / \mathrm{L})$ was decreased and lower than FMD 
group $(10.7 \pm 0.79 \mathrm{mmol} / \mathrm{L})$, as no significant difference with UC-MSCs group $(8.47 \pm 0.85 \mathrm{mmol} / \mathrm{L})$ (Fig. 4b). The results of IPGTT further showed UC-MSCs combined with FMD ameliorate glucose tolerance of DIO mice more than FMD cycles and no significant difference with UC-MSC infusion (Fig. 4C, d). Moreover, $\mathrm{HbA}_{1 \mathrm{c}}$ and serum insulin concentration remarkably declined by UC-MSCs combined with FMD, better than FMD cycles, like UC-MSC infusion (Fig. 4e-g). These results provided UC-MSCs combined with FMD same as UC-MSC infusion in maintaining glucose homeostasis.

\subsection{UC-MSCs Combined with FMD Regulated Lipid Metabolism Better than FMD Cycles}

To investigate whether UC-MSCs combined with FMD can further regulate lipid metabolisms of DIO mice. We analyzed the histological change of liver, skin and visceral fat. As expected, UC-MSCs combined with FMD markedly reduced the liver steatosis in DIO mice as same as FMD cycles and better than UC-MSC infusion, as examined by H\&E and Oil red $\mathrm{O}$ staining (Fig. 5a, b, Figure S4a). Consistently, the skin fatty layer thickness and the visceral adipocyte size were reduced by UC-MSCs combined with FMD more than FMD cycles and UC-MSC infusion (Fig. 5c, d, Figure S4b, c). Besides, UC-MSCs combined with FMD and FMD cycles both resulted in a reduction in HFD-fed body weight, and the weight loss in UC-MSCs combined with FMD group $(-1.68 \pm 0.30 \mathrm{~g})$ was more than FMD group $(-0.69 \pm 0.44 \mathrm{~g})$ (Fig. $5 \mathrm{e}, \mathrm{f})$. Meanwhile, the levels of serum TC, TG, FFA, AST and ALT in UC-MSCs combined with FMD group were considerably decreased and lower than UC-MSCs group (Fig. 5g-k). What's more, the levels of serum TC, TG and AST in UC-MSCs combined with FMD group were no significant difference with FMD group, but the levels of serum FFA and ALT in UC-MSCs combined with FMD group substantially lower than FMD group (Fig. 5g-k). These results suggested UC-MSCs combined with FMD better than FMD cycles in restoring lipid metabolisms.

\subsection{UC-MSCs Combined with FMD Suppressed Inflammation in DIO Mice}

To explore the mechanisms underlying synergistic effects of FMD and UC-MSCs. We analyzed the serum inflammation cytokine levels in different group. The concentrations of proinflammatory cytokines IL-1 $\beta$ (Fig. 6a) and IL-6 (Fig. 6b) were dramatically reduced by UC-MSC infusion and UC-MSCs combined with FMD, especially UC-MSCs combined with FMD which lower than UC-MSCs group, while did not change significantly after FMD cycles. However, the concentrations of proinflammatory cytokines TNF-a and IFNY were decreased by FMD cycles, UC-MSC infusion and UC-MSCs combined with FMD (Fig. 6c, d). Compared with FMD group, UC-MSCs and UC-MSCs combined with FMD group were lower than FMD group, together with UC-MSCs combined with FMD group were lower than UC-MSCs group (Fig. 6c, d). Moreover, FMD cycles, UC-MSC infusion and UC-MSCs combined with FMD all increased the concentration of the anti-inflammatory cytokine IL-10, but UC-MSCs combined with FMD were higher than FMD group and no significant difference with UC-MSCs group (Fig. 6e). Besides, the concentrations of serum TGF- $\beta$ were increased by UC-MSC infusion and UC-MSCs combined with FMD, with no change in FMD group, and no significant difference was detected between UC-MSC infusion and UC-MSCs combined with FMD group (Fig. 6f). These results displayed immunoregulatory function by UC-MSCs contributed to strengthen actions of FMD in T2D therapy.

\subsection{UC-MSCs Combined with FMD Regulated Lipid Metabolism in $\mathrm{db} / \mathrm{db}$ mice}


To confirm the therapeutic effect of UC-MSCs combined with FMD on T2D, we used $\mathrm{db} / \mathrm{db}$ mice to verify above results. The $\mathrm{db} / \mathrm{db}$ mice were divided into four groups: $\mathrm{db} / \mathrm{db}$, FMD, UC-MSCs $\left(1 \times 10^{6} \mathrm{cell} / \mathrm{dose}\right.$ in $0.2 \mathrm{~mL}$ PBS) and UC-MSCs combined with FMD. The fasting blood glucose in UC-MSCs combined with FMD group $(7.4 \pm 1.41 \mathrm{mmol} / \mathrm{L})$ was lower than FMD group $(10.6 \pm 0.81 \mathrm{mmol} / \mathrm{L})$, and no significant difference with UC-MSCs group (6.7 $\pm 1.22 \mathrm{mmol} / \mathrm{L}$ ) (Figure S3a). Besides, FMD cycles, UC-MSC infusion and UC-MSCs combined with FMD all could control weight gain in $\mathrm{db} / \mathrm{db}$ mice, FMD cycles $(3.08 \pm 0.96 \mathrm{~g})$ and UC-MSCs combined with FMD $(2.41 \pm 1.29 \mathrm{~g})$ were better than UC-MSC infusion $(4.84 \pm 0.81 \mathrm{~g})$ (Figure S3b. c).

Same as DIO mice model, the histopathological results supported by H\&E and Oil red $\mathrm{O}$ staining in $\mathrm{db} / \mathrm{db}$ mice showed liver steatosis, thickened skin fat layer and larger visceral adipocyte size in UC-MSCs combined with FMD group, in comparison with FMD cycles and UC-MSC infusion group (Fig. 7a-e). For the inhibition of proinflammatory cytokines IL- $1 \beta$ and IL- 6 and the promotion of anti-inflammatory cytokine IL-10 and TGF- $\beta$, the results obtained in $\mathrm{db} / \mathrm{db}$ mice model were consistent with those of DIO mice model (Fig. 7f-i).

\section{Discussion}

FMD has been recently tested in the research of prediabetic and diabetic treatment and has shown immense therapeutic potential particularly for controlling dyslipidemia, but there are still some deficiencies regarding it effects on the glucose metabolism $[10,12,15,28]$. Here, we investigated the effects of FMD and UC-MSC infusion on DIO type 2 diabetic mice and discovered that FMD indeed reduced weight gain and restored the lipid metabolism, but its capacity of controlling blood glucose was questionable. UC-MSC infusion can markedly decrease hyperinsulinemia and realized glycemic control, nevertheless, it has a little effect on dyslipidemia. Further experiments using combined UC-MSC infusion and FMD demonstrated effective regulation both of glucose and lipid metabolisms of DIO and db/db mice, which was based on immunoregulation of UC-MSCs. These results shed light on a promising approach to T2D with translational potential.

Diabetes mellitus is a chronic metabolic disease which requires continuous medical care and multifactorial risk reduction strategies. T2D, which accounts for $90-95 \%$ of diabetic prevalence, encompasses individuals who have insulin resistance and relative insulin deficiency [29]. It has been reported that calorie restriction or changes in dietary composition can induce a specific lipidome and metabolome reprogramming event in liver, which might have positive effects on diabetic treatment $[8,30]$. FMD, as a special intermittent fasting diet, can dramatically reduce TG, total and low-density lipoprotein cholesterol, resulting in a loss of total body fat reported by previous studies [10-12]. One study found that lipogenesis pathway and ketogenesis pathway enzymes in the liver of diabetic mice were reduced by dietary interventions. In addition, FMD reversed the enhanced autophagy, mitochondrial biogenesis, collagen deposition and endoplasmic reticulum stress in diabetic mice [31]. However, there are also reports claiming that mice receiving the alternate-day fasting regimen are more tolerant of glucose on the 
feeding day than on the fasting day, indicating that fasting might also impair the normal glucose metabolism. Meanwhile, the fasting blood glucose level fluctuated significantly during $\operatorname{FMD}[15,32]$.

UC-MSCs are highly pluripotent stem cells expressing pluripotent markers such as Oct-4, Sarbox-2 and cMyc [33]. There are increasing evidence indicating the therapeutic effects of UC-MSCs transplantation in a spectrum of diseases, including spinal cord injury, colitis and myocardial infarction, due to its capacity of secreting various cytokines and growth factors [34-37]. Furthermore, recent studies have unveiled that UC-MSC infusion potently promotes beta-cell function, which might be correlated with tissue repair or cytoprotective properties of MSCs [38]. They can also reverse insulin resistance and improve islet function by suppressing NLRP3 inflammasome-mediated inflammation and eliciting macrophages into an anti-inflammatory phenotype [39, 40], underlying their effects to lower blood glucose and $\mathrm{HbA}_{1 \mathrm{c}}$ without immediate or delayed toxicity $[22,23]$. However, there have been studies reported that the effects of UC-MSCs on improving lipid metabolism disorder are not quite satisfactory [24].

DIO mouse is an acquired obesity model induced by high-fat diet, which often appear obesity and diabetes-related symptoms[41]. In this study, we discovered that FMD cycles were effective in treating lipid metabolic disorders in DIO type 2 diabetic mice. But the capacity of FMD to reverse alterations in glucose homeostasis was indeed inferior than UC-MSCs, adding to the current knowledge of FMD efficacy on T2D. We also confirmed the glycemic control efficacy of UC-MSCs, while UC-MSC infusion did have less influences on ameliorating weight gain and dyslipidemia than FMD in T2D, which provides intriguing evidence for rethinking the translational strategy. These phenomena enlighten us to consider the treatment of diabetes with the combination of UC-MSCs and FMD. As proved here that UC-MSCs promoted FMD effects on ameliorating hyperglycemia and restoring the lipid metabolism in DIO type 2 diabetic mice, while FMD had little promotion effect on UC-MSCs.

Immune dysfunction has been increasingly recognized as an important pathogenesis of T2D, in which long-term activation of both innate and adaptive immune responses leads to chronic systemic inflammation contributing to insulin resistance and relative insulin deficiency [42-45]. In this regard, elevated levels of circulating inflammatory markers have been considered as a hallmark of T2D and an aggravation mechanism for its progression [46]. Several studies have shown the main target cells of inflammation to develop insulin resistance in T2D are adipocytes [47]. There is also evidence showing that proinflammatory cytokines including TNF- $a$, IL-1 $\beta$ and IFN- $\gamma$ disrupt the regulation of intracellular calcium in beta cells, thereby inhibiting the release of insulin. In addition, TNF-a increases the expression of islet amyloid polypeptide in beta cells, resulting in accelerated death [48, 49]. Given the important role of inflammation during the progression of diabetes, there are oral and injectable therapies being developed. For one instance, many studies have demonstrated that intensive insulin therapy significantly down-regulated serum IL-2, TNF-a, INF-y and IL-4 concentrations with up-regulation of IL-10 in diabetic patients, contributing to the anti-inflammatory status in treating these patients [50-52]. Metformin is one of the recommended first-line glucose-lowering medications for treating T2D [53]. Notably, metformin can reduce inflammatory cytokines, such as TNF- $a$, IL- 6 and IL-1, and induce the production of antiinflammatory cytokines, such as IL-4 and IL-10 [54, 55]. MSCs also exert the potent ability to ameliorate 
systemic inflammation and restore the homeostasis of the immune microenvironment, in which they reduce serum pro-inflammatory cytokines, including IL-6, IL-1a, IL-1 $1 \beta$ and IFN- $\gamma$, and promote EGF and IL$10[56,57]$. Here, we further confirmed immunoregulatory effects of UC-MSCs on T2D, which may serve as a pivotal mechanism underlying their therapeutic effects. Particularly, effects of FMD on inflammatory responses were significantly increased in combination with UC-MSCs, these phenomena in reducing circulating proinflammatory mediators and elevating anti-inflammatory cytokines may represent the normalization of immune function to a balanced status, thus decreasing systemic inflammatory response and restoring normal insulin resistance and relative insulin deficiency.

$\mathrm{db} / \mathrm{db}$ mice are a type of spontaneous obese diabetic mice whose leptin receptor mutation leads to leptin signaling pathway dysfunction, they also appear obesity and diabetes-related symptoms such as insulin resistance, significant increases in blood glucose levels and hepatic steatosis[58]. We finally demonstrated the role of UC-MSCs combined with FMD in $\mathrm{db} / \mathrm{db}$ mouse model. Similar to DIO mice, it was showed excellent capabilities in ameliorating hyperglycemia and regulating lipid metabolism. Since patients with T2D have a growing prevalence of overweight and dyslipidemia [59], based on the regulation of lipid metabolism by FMD, our strategy realized the purpose of further promoting the regulation of glucose metabolism by UC-MSCs, which ultimately provides a new idea for the treatment of T2D.

\section{Conclusions}

We established a strategy that combined UC-MSC infusion and FMD were effective in treating T2D, which synergistically attenuated hyperglycemia and improved the lipid metabolism through immunoregulation. This work is of great significance for the development of novel clinical T2D approaches.

\section{Abbreviations}

ALT Alanine aminotransferase

AST Aspartate transaminase

DIO Diet-induced obese

FFA Free fatty acid concentrations

FMD Fasting-mimicking diet

HFD High-fat diet

HGF Hepatic growth factor

NO Nitric oxide 
OCT Optimal cutting temperature compound

$\mathrm{PGE}_{2}$ Prostaglandin $\mathrm{E}_{2}$

RCD Regular chow diet

RF Refeeding

TC Total cholesterol

TG Triglyceride

T2D Type 2 diabetes

UC-MSCs Human umbilical cord-derived mesenchymal stem cells

\section{Declarations}

Ethics approval and consent to participate: The laboratory animals were handled in accordance with Guidelines for the Care and Use of Laboratory Animals and the Animal Welfare Act in China. Consent for publication: Not applicable. Availability of data and materials: The datasets used and analysed during the current study are available from the corresponding author on reasonable request. Competing interests: The authors declare that they have no competing interest. Funding: The National Key Research and Development Program of China (2017YFA0104900); Xi'an Fourth Hospital Incubation Fund Project (2019FZ46); The National Natural Science Foundation of China (81930025); The Young Elite Scientist Sponsorship Program by CAST of China (2019QNRC001); The Postdoctoral Innovative Talents Support Program of China (BX20190380); The General Program of China Postdoctoral Science Foundation (2019M663986). Authors' contributions: N.Z., Y.G. and L.B.: conception and design, collection and/or assembly of data, data analysis and interpretation, manuscript writing; J. L., H.A., F.P., R.C., J.C. and H.N.: provision of study material or patients, collection and/or assembly of data, data analysis and interpretation; B.S., F.J. and C.H.: conception and design, data analysis and interpretation, financial support, manuscript writing, final approval of manuscript. Acknowledgements: Not applicable.

\section{References}

1. Harding JL, Pavkov ME, Magliano DJ, Shaw JE, Gregg EW. Global trends in diabetes complications: a review of current evidence. Diabetologia. 2019;62:3-16.

2. Chan JM, Rimm EB, Colditz GA, Stampfer MJ, Willett WC. Obesity, fat distribution, and weight gain as risk factors for clinical diabetes in men. Diabetes Care. 1994;17:961-9.

3. Kratz M, Baars T, Guyenet S. The relationship between high-fat dairy consumption and obesity, cardiovascular, and metabolic disease. Eur J Nutr. 2013;52:1-24. 
4. Richard J, Lingvay I. Hepatic steatosis and Type 2 diabetes: current and future treatment considerations. Expert Rev Cardiovasc Ther. 2014;9:321-8.

5. Williamson RM, Price JF, Glancy S, Perry E, Nee LD, Hayes PC, et al. Prevalence of and risk factors for hepatic steatosis and nonalcoholic Fatty liver disease in people with type 2 diabetes: the Edinburgh Type 2 Diabetes Study. Diabetes Care. 2011;34:1139-44.

6. Toledo FG, Sniderman AD, Kelley DE. Influence of hepatic steatosis (fatty liver) on severity and composition of dyslipidemia in type 2 diabetes. Diabetes Care. 2006;29:1845-50.

7. Taskinen MR, Boren J. New insights into the pathophysiology of dyslipidemia in type 2 diabetes. Atherosclerosis. 2015;239:483-95.

8. Mariona J, Alba N, Omar R. Caloric restriction reveals a metabolomic and lipidomic signature in liver of male mice. Aging Cell. 2014;13:828-37.

9. Kevork H, Jon JR, Richard W. Caloric restriction increases gluconeogenic and transaminase enzyme activities in mouse liver. Exp Gerontol. 2003;38:267-78.

10. Min W, Brandhorst S, Shelehchi M. Fasting-mimicking diet and markers/risk factors for aging, diabetes, cancer, and cardiovascular disease. Sci Transl Med. 2017;9:eaai8700.

11. Choi IY, Lee C, Longo VD. Nutrition and fasting mimicking diets in the prevention and treatment of autoimmune diseases and immunosenescence. Molecular cellular endocrinology. 2017;455:4-12.

12. Wei S, Han R, Zhao J, Wang S, Huang M, Wang Y, et al. Intermittent administration of a fastingmimicking diet intervenes in diabetes progression, restores beta cells and reconstructs gut microbiota in mice. Nutrition metabolism. 2018;15:80.

13. Ugochukwu NH, Figgers CL. Caloric restriction inhibits up-regulation of inflammatory cytokines and TNF-alpha, and activates IL-10 and haptoglobin in the plasma of streptozotocin-induced diabetic rats. J Nutr Biochem. 2007;18:120-6.

14. Crisostomo J, Rodrigues L, Matafome P, Amaral C, Nunes E, Louro T, et al. Beneficial effects of dietary restriction in type 2 diabetic rats: the role of adipokines on inflammation and insulin resistance. Br J Nutr. 2010;104:76-82.

15. Horne BD, Grajower MM, Anderson JL. Limited Evidence for the Health Effects and Safety of Intermittent Fasting Among PatientsWith Type 2 Diabetes. JAMA-J Am Med Assoc. 2020;324:341-2.

16. Pittenger MF, Mackay AM, Beck SC, Jaiswal RK, Douglas R, Mosca JD, et al. Multilineage potential of adult human mesenchymal stem cells. Science. 1999;284:143-7.

17. Nicola MD, Carlo-Stella C, Magni M, Milanesi M, Longoni PD, Matteucci P, et al. Human bone marrow stromal cells suppress T-lymphocyte proliferation induced by cellular or nonspecific mitogenic stimuli. Blood. 2002;99:3838-43.

18. Yaochite JNU, Caliari-Oliveira C, De-Souza LEB, Neto LS, Palma PV, Covas DT, et al. Therapeutic efficacy and biodistribution of allogeneic mesenchymal stem cells delivered by intrasplenic and intrapancreatic routes in streptozotocin-induced diabetic mice. Stem Cell Res Ther. 2015;6:31. 
19. Ren G, Zhao X, Zhang L, Zhang J, L'Huillier A, Ling W, et al. Inflammatory cytokine-induced intercellular adhesion molecule- 1 and vascular cell adhesion molecule-1 in mesenchymal stem cells are critical for immunosuppression. Journal of immunology. 2010;184:2321-8.

20. Maedler K, Yeung TY, Seeberger KL, Kin T, Adesida A, Jomha N, et al. Human Mesenchymal Stem Cells Protect Human Islets from Pro-Inflammatory Cytokines. PLoS ONE. 2012;7:e38189.

21. English K, French A, Wood KJ. Mesenchymal stromal cells: facilitators of successful transplantation? Cell stem cell. 2010;7:431-42.

22. Hu J, Wang Y, Gong H, Yu C, Guo C, Wang F, et al. Long term effect and safety of Wharton's jellyderived mesenchymal stem cells on type 2 diabetes. Experimental therapeutic medicine. 2016;12:1857-66.

23. Guan LX, Guan H, Li HB, Ren CA, Liu L, Chu JJ, et al. Therapeutic efficacy of umbilical cord-derived mesenchymal stem cells in patients with type 2 diabetes. Experimental therapeutic medicine. 2015;9:1623-30.

24. Liu GY, Liu J, Wang YL, Liu Y, Shao Y, Han Y, et al. Adipose-Derived Mesenchymal Stem Cells Ameliorate Lipid Metabolic Disturbance in Mice. Stem cells translational medicine. 2016;5:1162-70.

25. Cheng CW, Villani V, Buono R, Wei M, Kumar S, Yilmaz OH, et al. Fasting-Mimicking Diet Promotes Ngn3-Driven beta-Cell Regeneration to Reverse Diabetes. Cell. 2017;168:775-88.

26. Cécile DB, Najar M, Raicevic G, Meuleman N, Pieters K, Stamatopoulos B, et al. A Rapid, Simple, and Reproducible Method for the Isolation of Mesenchymal Stromal Cells from Wharton's Jelly Without Enzymatic Treatment. Stem Cells Dev. 2011;20:547.

27. Majore I, Moretti P, Stahl F, Hass R, Kasper C. Growth and Differentiation Properties of Mesenchymal Stromal Cell Populations Derived from Whole Human Umbilical Cord. Stem Cell Rev Rep. 2010;7:1731.

28. Tay A, Pringle H, Penning E, Plank LD, Murphy R. PROFAST: A Randomized Trial Assessing the Effects of Intermittent Fasting and Lacticaseibacillus rhamnosus Probiotic among People with Prediabetes. Nutrients. 2020;12:3530.

29. Amer Diabet Assoc. Diagnosis and Classification of Diabetes Mellitus. Diabetes Care. 2009;33:62-S9.

30. Vaiserman AM, Lushchak OV, Koliada AK. Anti-aging pharmacology: Promises and pitfalls. Ageing Res Rev. 2016;31:9-35.

31. Kim KE, Jung Y, Min S, Nam M, Heo RW, Jeon BT, et al. Caloric restriction of $d b / d b$ mice reverts hepatic steatosis and body weight with divergent hepatic metabolism. Scientific reports. 2016;6:30111.

32. Wei S, Han R, Zhao J, Wang S, Huang M, Wang Y, et al. Intermittent administration of a fastingmimicking diet intervenes in diabetes progression, restores beta cells and reconstructs gut microbiota in mice. Nutr Metab-Lond. 2018;15:80.

33. Carlin R, Davis D, Weiss M, Schultz B, Troyer D. Expression of early transcription factors Oct-4, Sox-2 and Nanog by porcine umbilical cord (PUC) matrix cells. Reprod Biol Endocrin. 2006;4:8. 
34. Baraniak PR, McDevitt TC. Stem cell paracrine actions and tissue regeneration. Regenerative medicine. 2010;5:121-43.

35. Hu SL, Luo HS, Li JT, Xia YZ, Li L, Zhang LJ, et al. Functional recovery in acute traumatic spinal cord injury after transplantation of human umbilical cord mesenchymal stem cells. Critical care medicine. 2010;38:2181-9.

36. Sala E, Genua M, Petti L, Anselmo A, Arena V, Cibella J, et al. Mesenchymal Stem Cells Reduce Colitis in Mice via Release of TSG6, Independently of Their Localization to the Intestine. Gastroenterology. 2015;149:163-76.

37. Lee RH, Pulin AA, Seo MJ, Kota DJ, Ylostalo J, Larson BL, et al. Intravenous hMSCs improve myocardial infarction in mice because cells embolized in lung are activated to secrete the antiinflammatory protein TSG-6. Cell stem cell. 2009;5:54-63.

38. Sun X, Hao H, Han Q, Song X, Liu J, Dong L, et al. Human umbilical cord-derived mesenchymal stem cells ameliorate insulin resistance by suppressing NLRP3 inflammasome-mediated inflammation in type 2 diabetes rats. Stem Cell Res Ther. 2017;8:241.

39. Yin Y, Hao H, Cheng Y, Zang L, Liu J, Gao J, et al. Human umbilical cord-derived mesenchymal stem cells direct macrophage polarization to alleviate pancreatic islets dysfunction in type 2 diabetic mice. Cell death disease. 2018;9:760.

40. Xie Z, Hao H, Tong C, Cheng Y, Liu J, Pang Y, et al. Human umbilical cord-derived mesenchymal stem cells elicit macrophages into an anti-inflammatory phenotype to alleviate insulin resistance in type 2 diabetic rats. Stem cells. 2016;34:627-39.

41. Li B, Cheng Y, Yu SY, Zang L, Yin Y, Liu J, et al. Human Umbilical Cord-Derived Mesenchymal Stem Cell Therapy Ameliorates Nonalcoholic Fatty Liver Disease in Obese Type 2 Diabetic Mice. Stem Cells Int. 2019; 2019: 1-12.

42. Luciano P, José CF. Role of pro- and anti-inflammatory phenomena in the physiopathology of type 2 diabetes and obesity. World J Biol Chem. 2017;8:120-8.

43. Zhao H, Huang X, Jiao J, Zhang H, Liu J, Qin W, et al. Protein phosphatase 4 (PP4) functions as a critical regulator in tumor necrosis factor (TNF)-alpha-induced hepatic insulin resistance. Scientific reports. 2015;5:18093.

44. Donath MY, Dinarello CA, Mandrup-Poulsen T. Targeting innate immune mediators in type 1 and type 2 diabetes. Nature reviews Immunology. 2019;19:734-46.

45. Furman D, Campisi J, Verdin E, Carrera-Bastos P, Targ S, Franceschi C, et al. Chronic inflammation in the etiology of disease across the life span. Nature medicine. 2019;25:1822-32.

46. Donath MY, Boni-Schnetzler M, Ellingsgaard H, Ehses JA. Islet inflammation impairs the pancreatic beta-cell in type 2 diabetes. Physiology. 2009;24:325-31.

47. Agrawal NK, Kant S. Targeting inflammation in diabetes: Newer therapeutic options. World journal of diabetes. 2014;5:697-710.

48. Cai K, Qi D, Wang O, Chen J, Liu X, Deng B, et al. TNF-alpha acutely upregulates amylin expression in murine pancreatic beta cells. Diabetologia. 2011;54:617-26. 
49. Masters SL, Dunne A, Subramanian SL, Hull RL, Tannahill GM, Sharp FA, et al. Activation of the NLRP3 inflammasome by islet amyloid polypeptide provides a mechanism for enhanced IL-1beta in type 2 diabetes. Nature immunology. 2010;11:897-904.

50. Nekoua MP, Fachinan R, Atchamou AK, Nouatin O, Amoussou-Guenou D, Amoussou-Guenou MK, et al. Modulation of immune cells and Th1/Th2 cytokines in insulin-treated type 2 diabetes mellitus. Afr Health Sci. 2016;16:712-24.

51. Chen H, Ren A, Hu S, Mo W, Xin X, Jia W. The significance of tumor necrosis factor-alpha in newly diagnosed type 2 diabetic patients by transient intensive insulin treatment. Diabetes Res Clin Pr. 2007;75:327-32.

52. Noh YH, Lee SM, Kim EJ, Kim DY, Lee H, Lee JH, et al. Improvement of cardiovascular risk factors in patients with type 2 diabetes after long-term continuous subcutaneous insulin infusion. Diab/Metab Res Rev. 2008;24:384-91.

53. Wang CP, Lorenzo C, Habib SL, Jo B, Espinoza SE. Differential effects of metformin on age related comorbidities in older men with type 2 diabetes. J Diabetes Complicat. 2017;31:679-86.

54. Chen W, Liu X, Ye S. Effects of metformin on blood and urine pro-inflammatory mediators in patients with type 2 diabetes. J Inflamm-Lond. 2016;13:34.

55. Cameron AR, Morrison VL, Levin D, Mohan M, Forteath C, Beall C, et al. Anti-Inflammatory Effects of Metformin Irrespective of Diabetes Status. Circulation research. 2016;119:652-65.

56. Li Y, Liu J, Liao G, Zhang J, Chen Y, Li L, et al. Early intervention with mesenchymal stem cells prevents nephropathy in diabetic rats by ameliorating the inflammatory microenvironment. Int $\mathrm{J}$ Mol Med. 2018;41:2629-39.

57. Gao LR, Zhang NK, Zhang Y, Chen Y, Wang L, Zhu Y, et al. Overexpression of apelin in Wharton' jelly mesenchymal stem cell reverses insulin resistance and promotes pancreatic beta cell proliferation in type 2 diabetic rats. Stem Cell Res Ther. 2018;9:339.

58. Guo M, Ricardo SD, Deane JA, Shi M, Cullen-McEwen L, Bertram JF. A stereological study of the renal glomerular vasculature in the $\mathrm{db} / \mathrm{db}$ mouse model of diabetic nephropathy. J Anat. 2005;207:81321.

59. Garg SK. New therapies for diabetes management. Diabetes Technol The. 2013;15:126-S35.

\section{Figures}



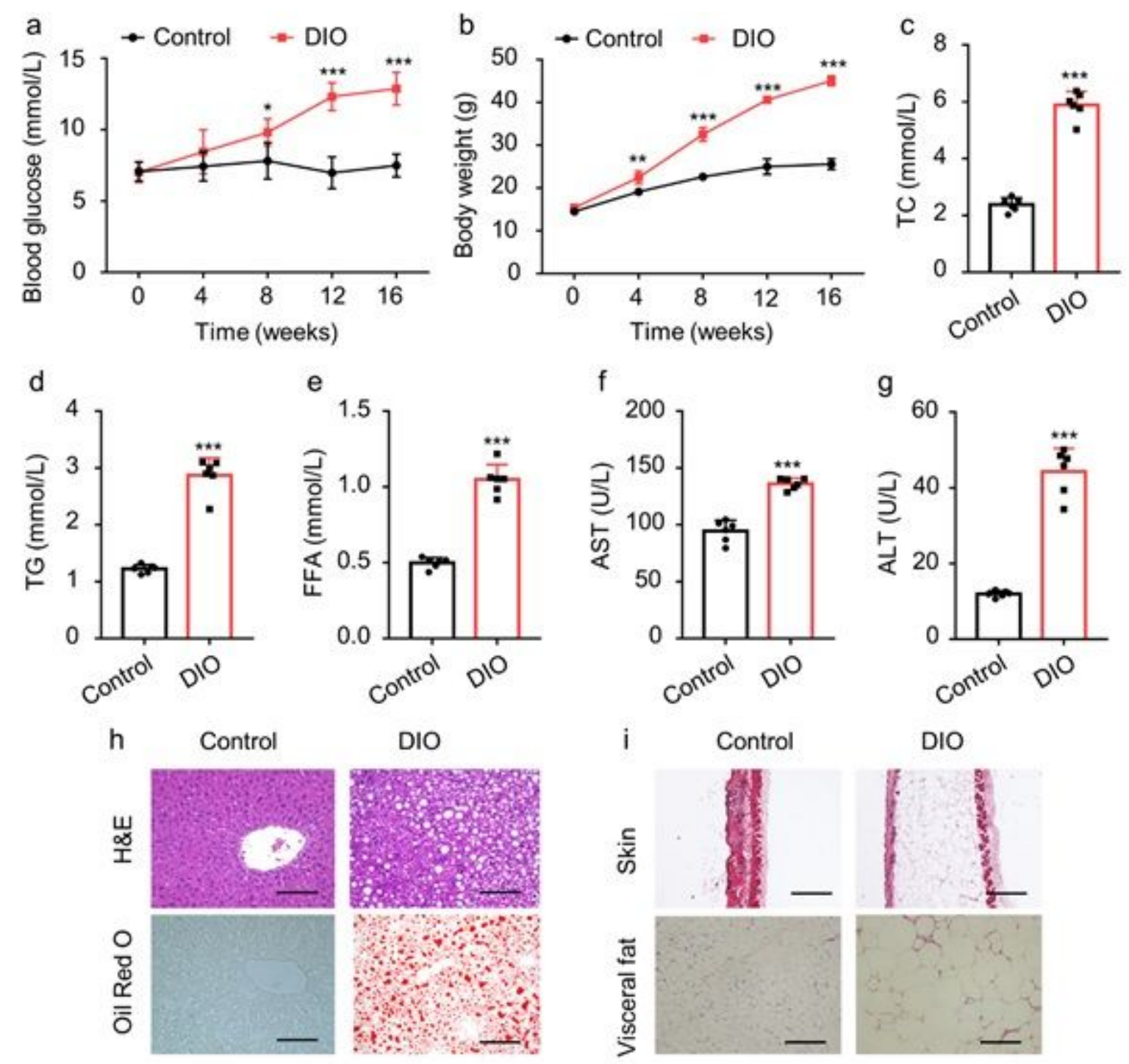

DIO
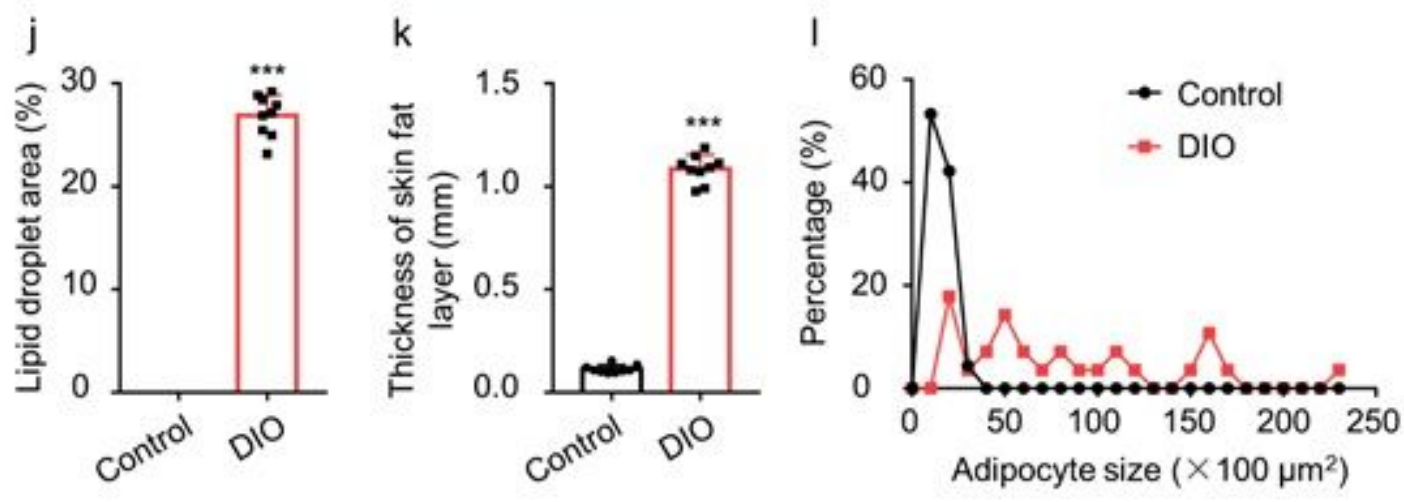

\section{Figure 1}

Metabolic studies in control and DIO mice. $(a, b)$ : Fasting blood glucose levels and body weight were determined every 4 weeks within 16 weeks. (c-g): The levels of serum TC, TG, FFA, AST and ALT in Control and DIO mice were detected by ELISA. (h): Liver steatosis were analyzed through staining with H\&E (Scale bar, $100 \mu \mathrm{m}$ ) and Oil Red O (Scale bar, $200 \mu \mathrm{m}$ ). (i): H\&E staining of skin (Scale bar, $1 \mathrm{~mm}$ ) and visceral fat (Scale bar, $100 \mu \mathrm{m})$. (j): The quantification of lipid accumulation in (h). (k): The quantification of 
thickness of subcutaneous fat layer in (i). (I): The quantification of visceral adipocytes size in (i). The data are expressed as mean values $\pm S D$. $n=6$ mice per group. ${ }^{*} P<0.05, \star \star P<0.01,{ }^{\star \star *} P<0.001$.
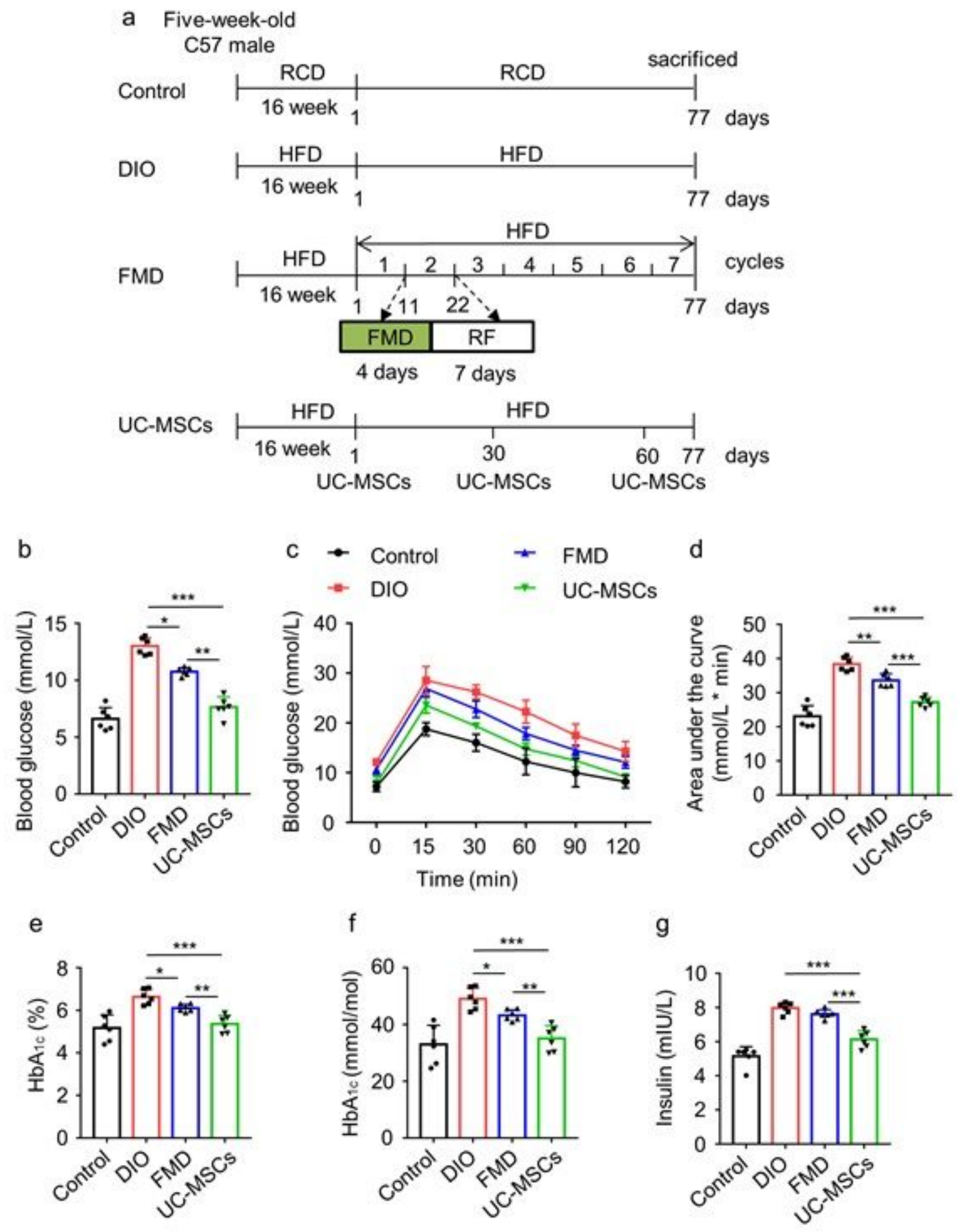

Figure 2

UC-MSC infusion improved glucose homeostasis in DIO mice better than FMD cycles. (a): Experimental scheme to determine effects of the periodic FMD and UC-MSCs on DIO mice. Each FMD cycle entails 4 days FMD and 7 days of refeeding (RF), which forms 11 days per cycle for 7 cycles. During refeeding, mice received a HFD identical to that given prior to the FMD. Control and UC-MSCs group have access to 
ad libitum feeding. (b): Fasting blood glucose levels were monitored after fasting $6 \mathrm{~h}$ at sacrificed. (c, d): Glucose tolerance was assessed by IPGTT. AUC above baseline was calculated as an index of glucose tolerance. (e-g): ELISA analyzed $\mathrm{HbA1c}, \mathrm{Hb}$ and serum insulin. The data are expressed as mean values \pm SD. $\mathrm{n}=6$ mice per group. ${ }^{*} \mathrm{P}<0.05,{ }^{*} \mathrm{P}<0.01,{ }^{*} * \mathrm{P}<0.001$.

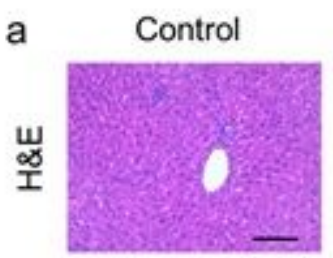

b

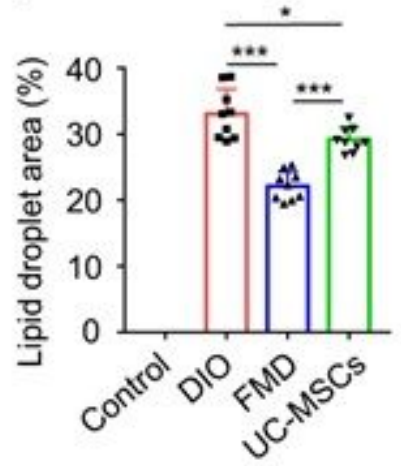

e

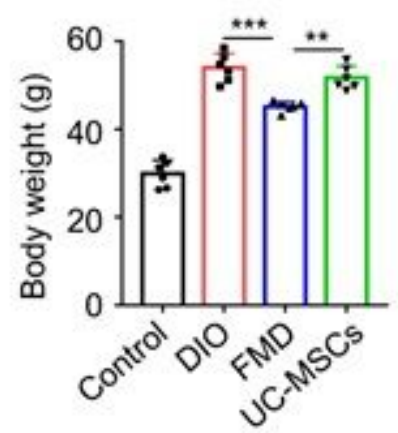

DIO

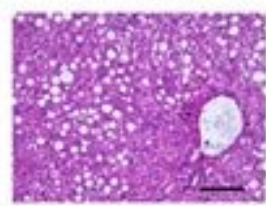

C
FMD

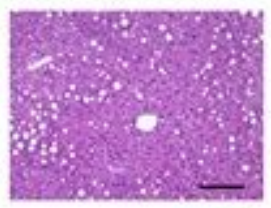

UC-MSCs

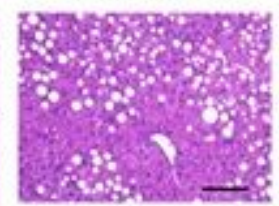

d
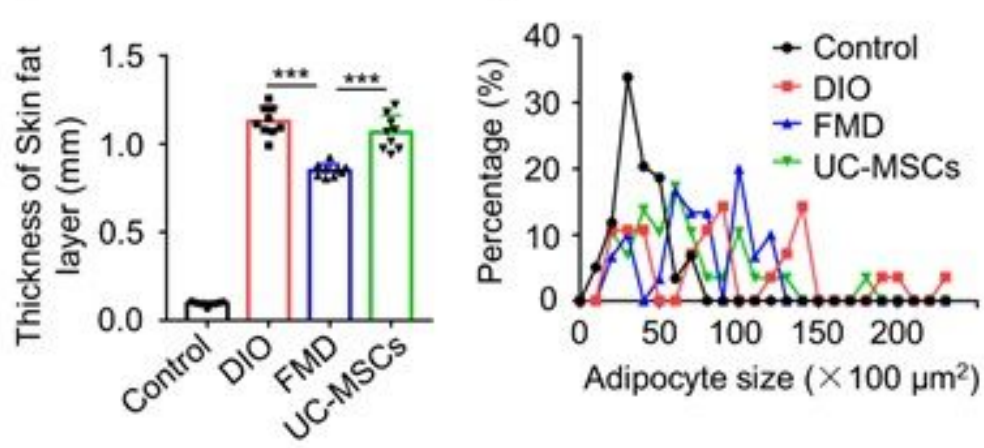

f
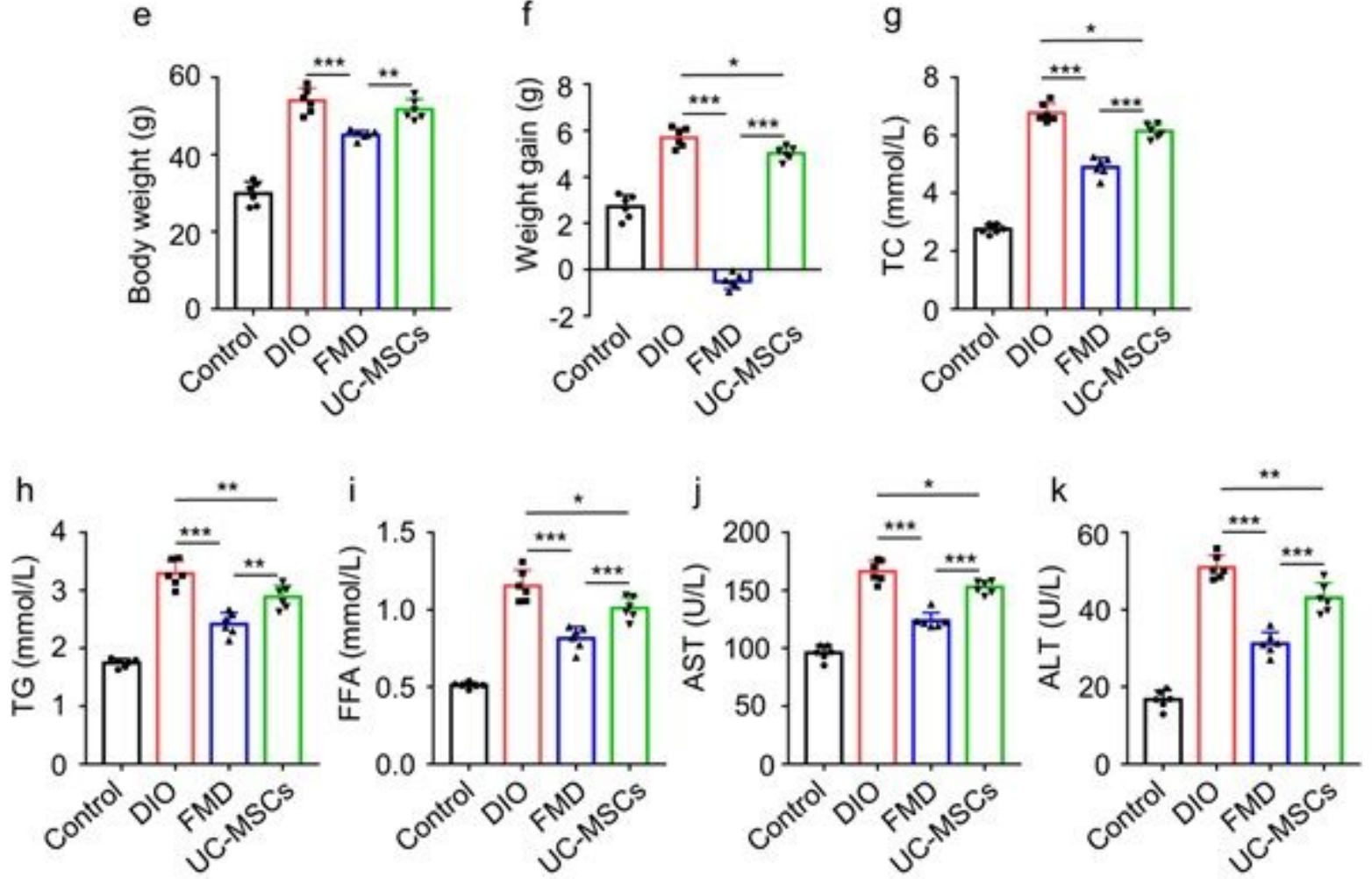

Figure 3

FMD cycles regulated lipid metabolism in DIO mice better than UC-MSC infusion. (a): Liver steatosis were analyzed through staining with H\&E (Scale bar, $100 \mu \mathrm{m}$ ). (b): The quantification of lipid accumulation in (a). (c): Quantification of thickness of subcutaneous fat layer. (d): Quantification of visceral adipocytes size. (e, f): Body weights were determined after fasting $6 \mathrm{~h}$ at sacrificed. $(\mathrm{g}-\mathrm{k})$ : The levels of serum TC, TG, 
FFA, AST and ALT were detected by ELISA. The data are expressed as mean values \pm SD. $n=6$ mice per group. ${ }^{*} \mathrm{P}<0.05,{ }^{*} \mathrm{P}<0.01,{ }^{*} * \mathrm{P}<0.001$.

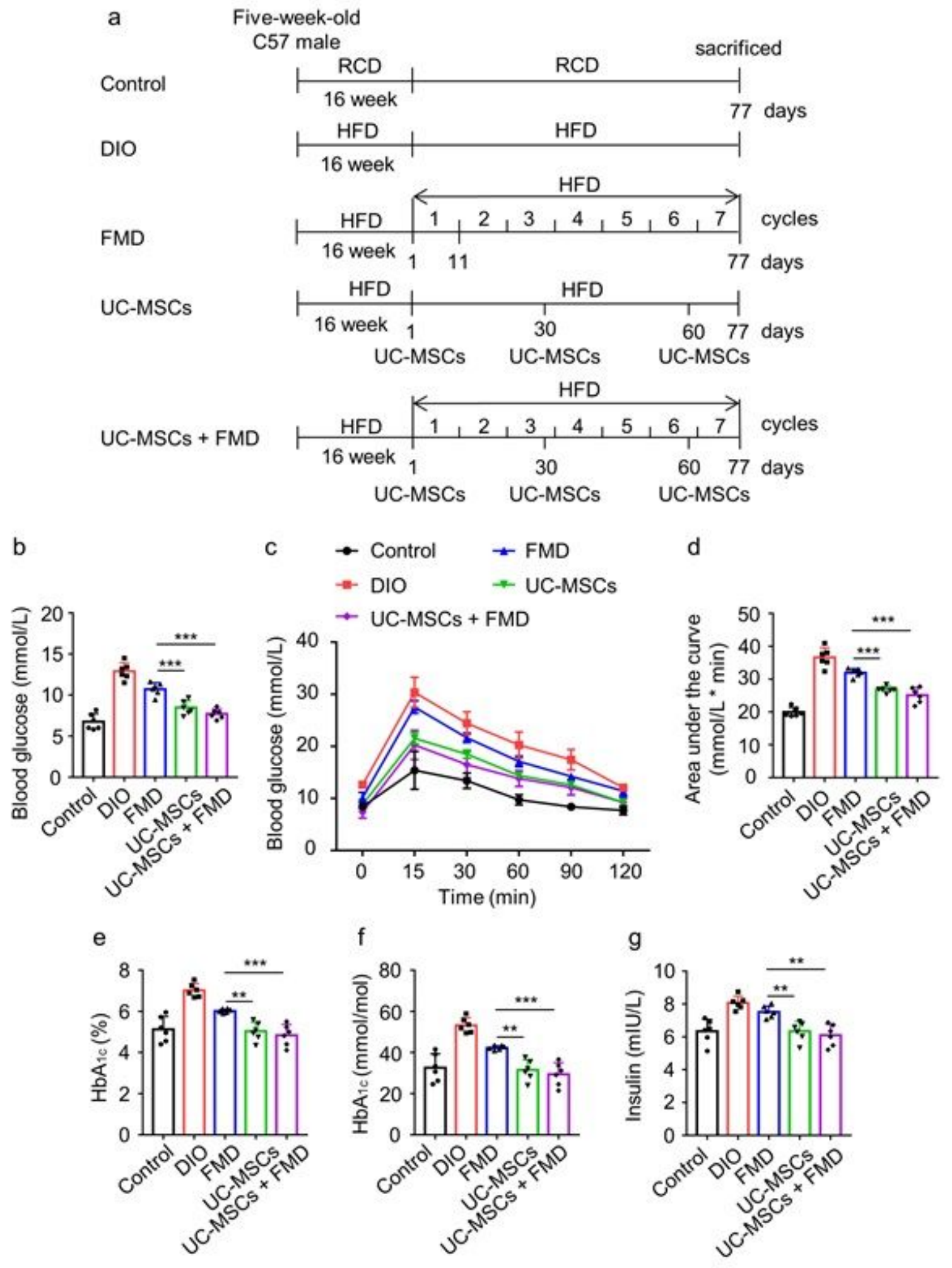

Figure 4

UC-MSCs combined with FMD improved glucose homeostasis as UC-MSC infusion. (a): Experimental scheme to determine effects of the periodic FMD and UC-MSCs on DIO mice. Each FMD cycle entails 4 days FMD and 7 days of refeeding (RF), which forms 11 days per cycle for 7 cycles. During refeeding, 
mice received a HFD identical to that given prior to the FMD. Control and UC-MSCs group have access to ad libitum feeding. (b): Fasting blood glucose levels were monitored after fasting $6 \mathrm{~h}$ at sacrificed. (c, d): Glucose tolerance was assessed by IPGTT. AUC above baseline was calculated as an index of glucose tolerance. (e-g): ELISA analyzed $\mathrm{HbA} 1 \mathrm{c}, \mathrm{Hb}$ and serum insulin. The data are expressed as mean values \pm SD. $\mathrm{n}=6$ mice per group. ${ }^{*} \mathrm{P}<0.05,{ }^{*} \mathrm{P}<0.01,{ }^{*} * \mathrm{P}<0.001$.
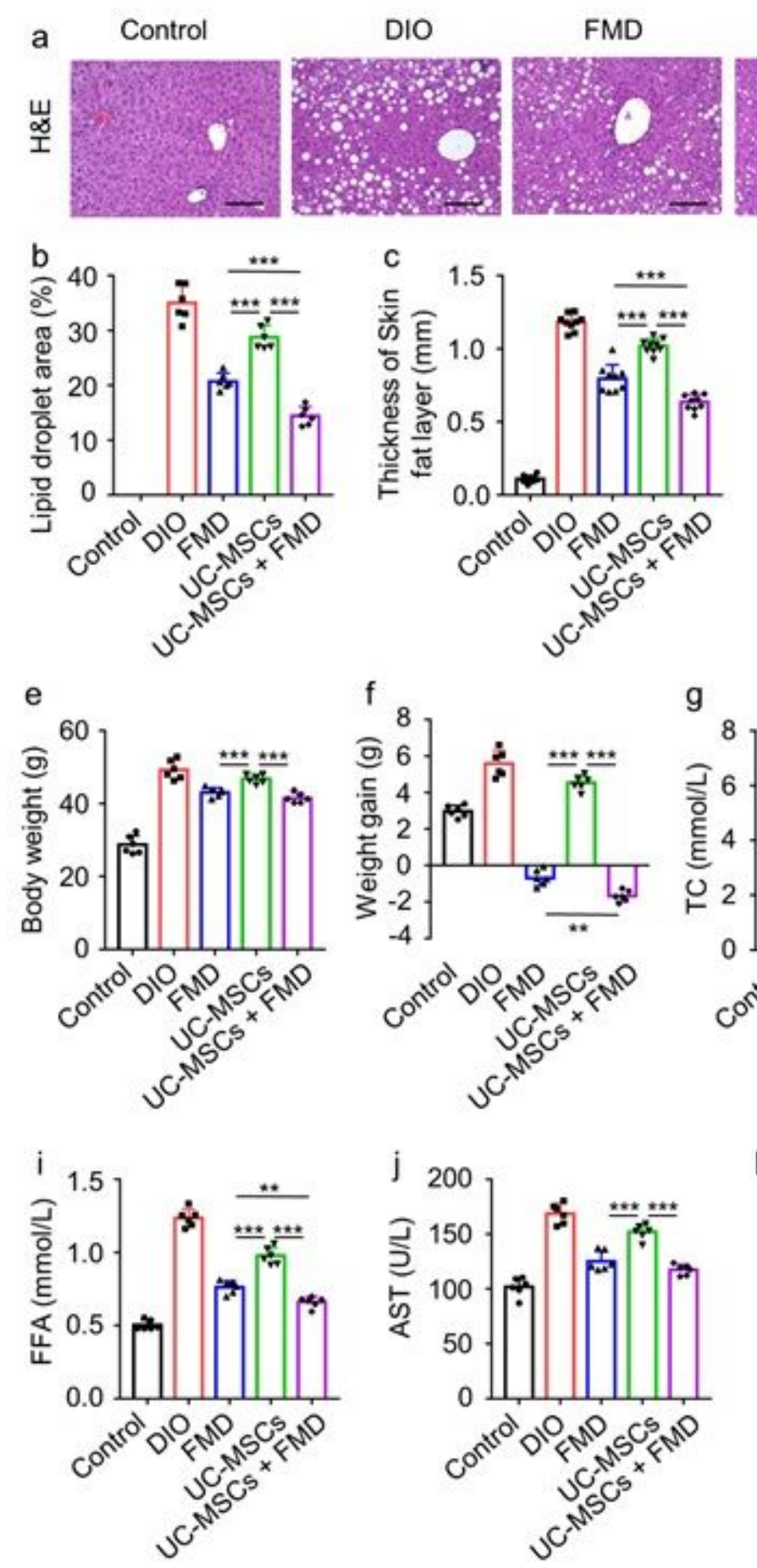
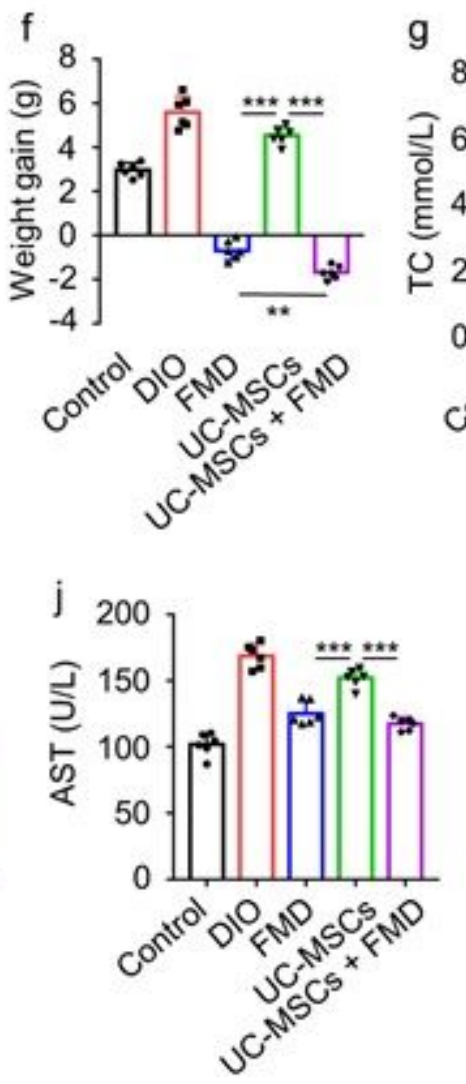

g
UC-MSCs UC-MSCs + FMD
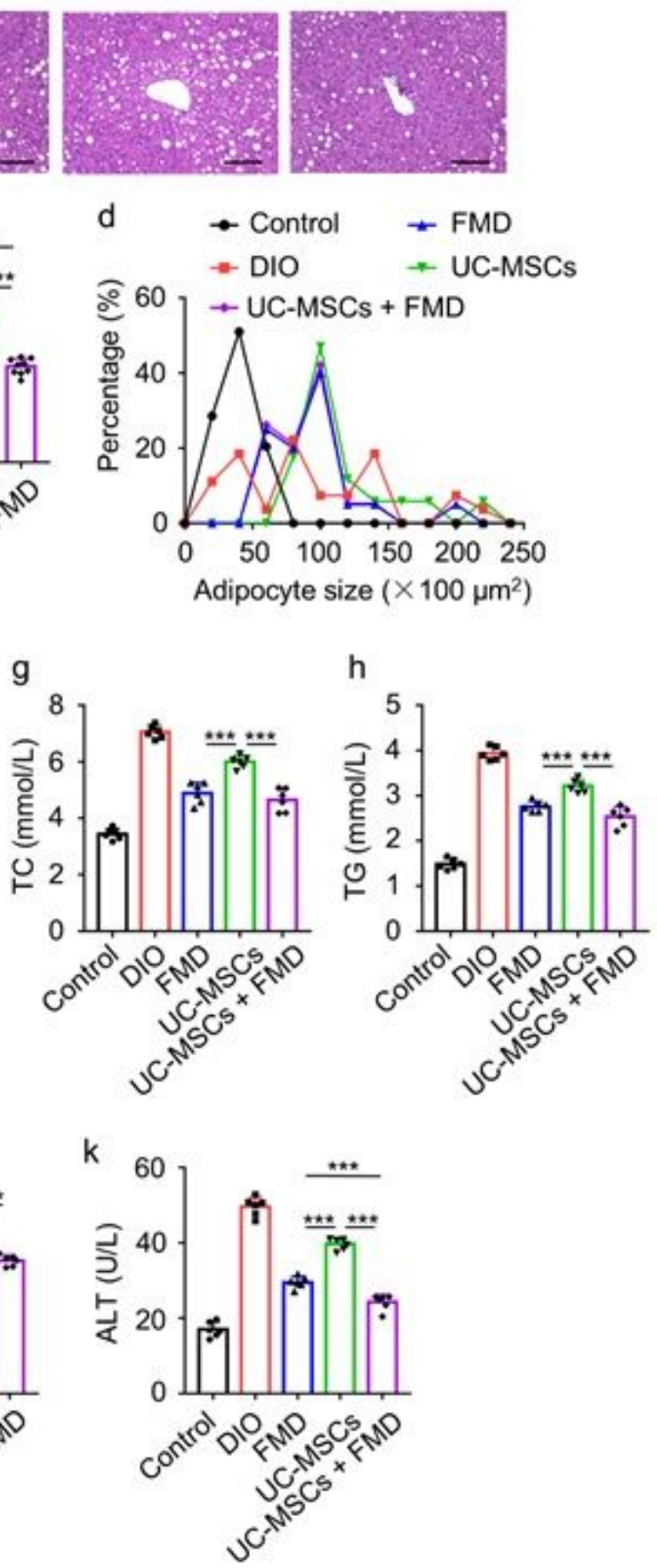

Figure 5

UC-MSCs combined with FMD regulated lipid metabolism better than FMD cycles. (a): Liver steatosis were analyzed through staining with H\&E (Scale bar, $100 \mu \mathrm{m})$. (b): The quantification of lipid 
accumulation in (a). (c): Quantification of thickness of subcutaneous fat layer. (d): Quantification of visceral adipocytes size quantification. $(e, f)$ : Body weights were determined after fasting $6 \mathrm{~h}$ at sacrificed. ( $\mathrm{g}-\mathrm{k})$ : The levels of serum TC, TG, FFA, AST and ALT were detected by ELISA. The data are expressed as mean values $\pm S D$. $n=6$ mice per group. ${ }^{*} P<0.05, * * P<0.01$, ${ }^{\star \star *} P<0.001$.
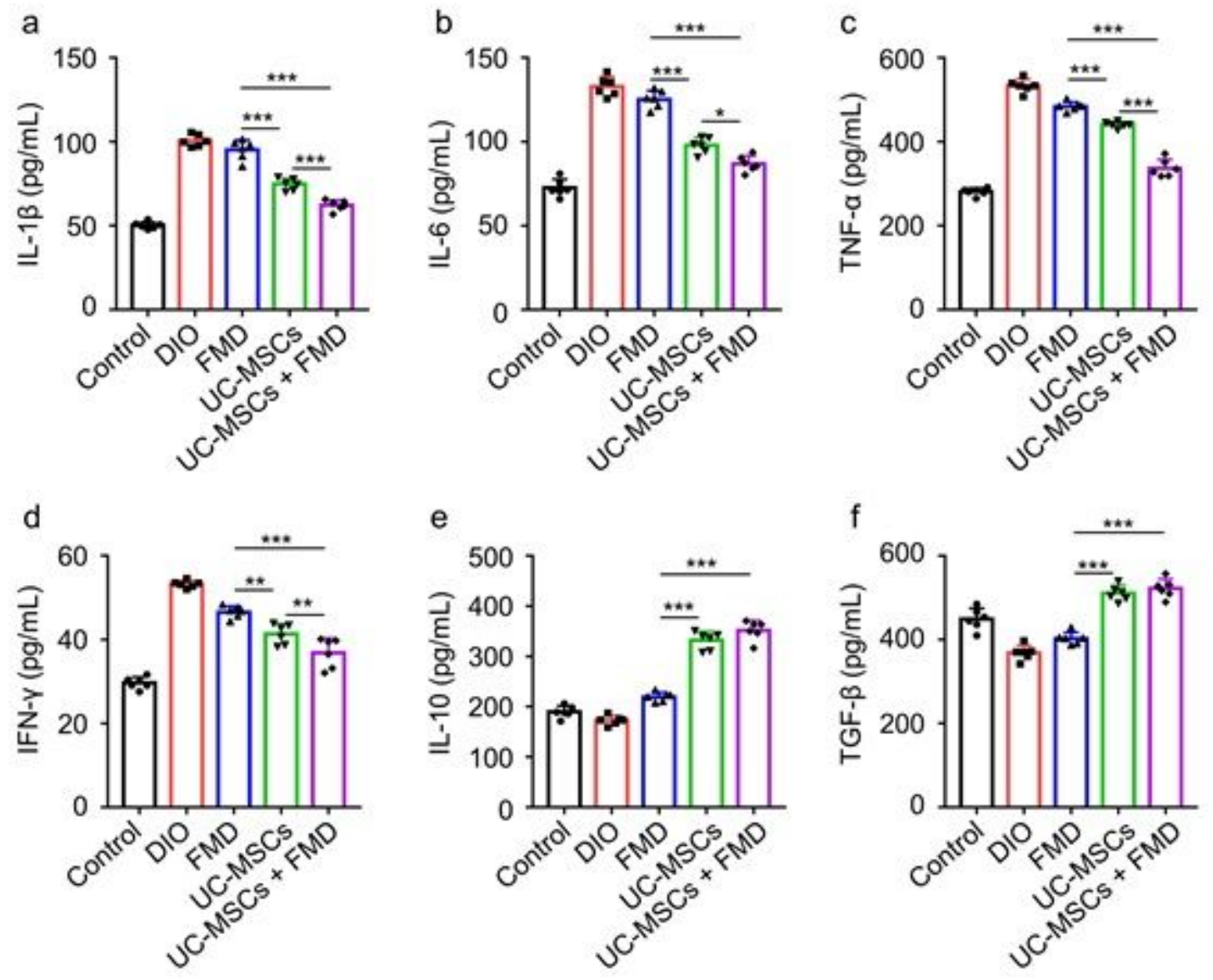

Figure 6

UC-MSCs combined with FMD suppressed inflammation. (a-f): ELISA analysis of serum IL-1 $\beta$, IL-6, TNF-a, IFN- $\gamma$, IL-10 and TGF- $\beta$ in Control, DIO, FMD, UC-MSCs and UC-MSCs + FMD groups. The data are expressed as mean values \pm SD. $n=6$ mice per group. ${ }^{*} P<0.05, * * P<0.01,{ }^{\star} * \star P<0.001$. 

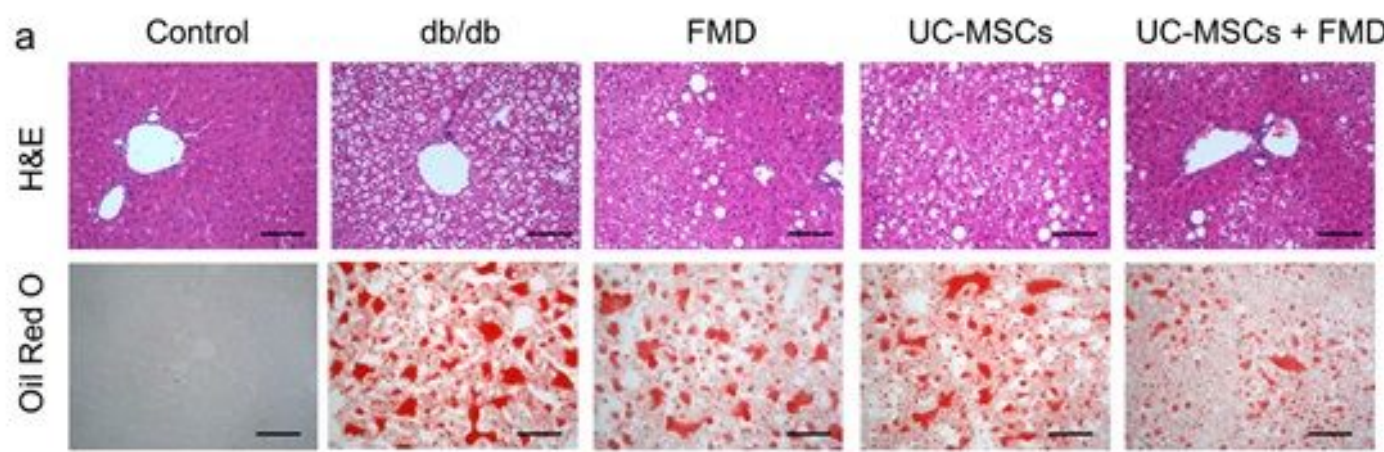

b

Control
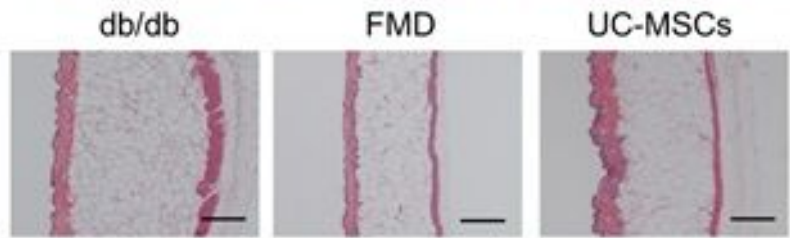

UC-MSCs + FMD
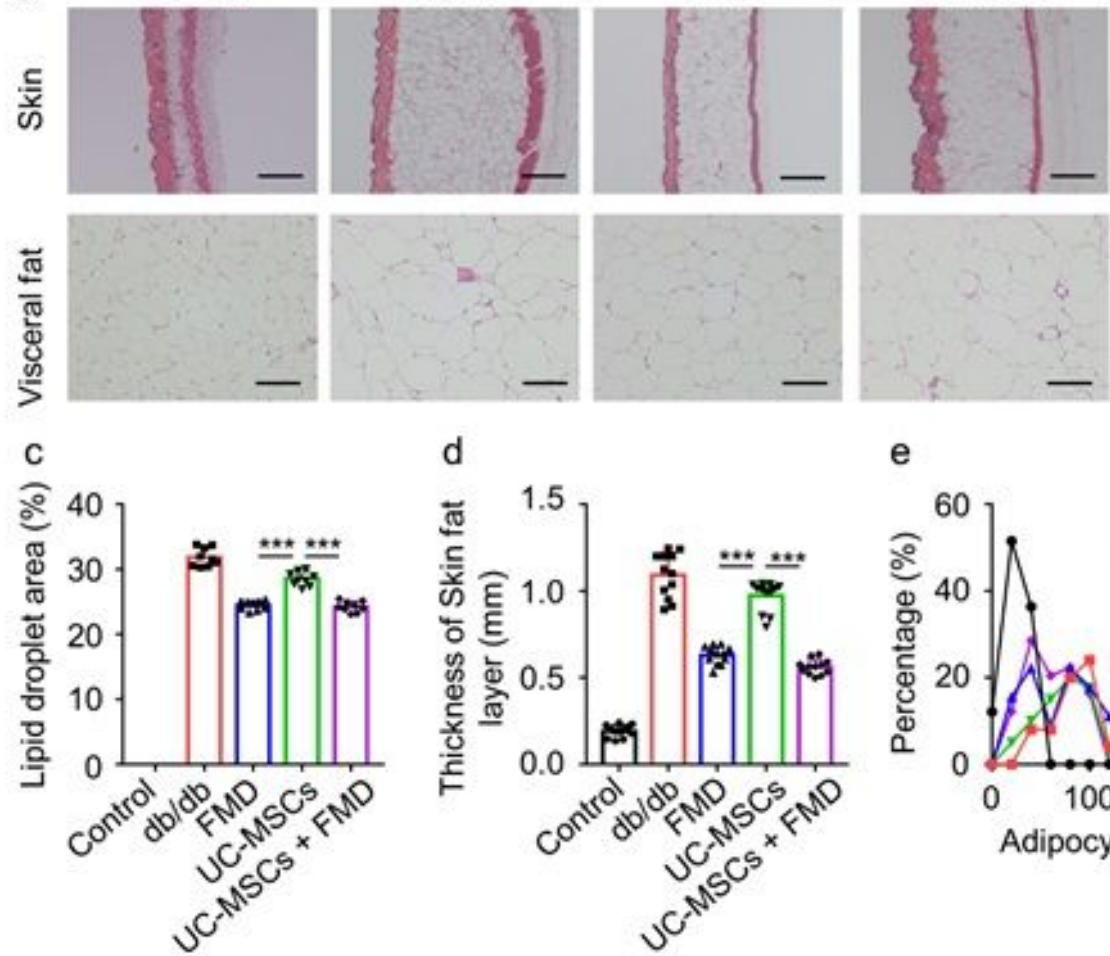

e
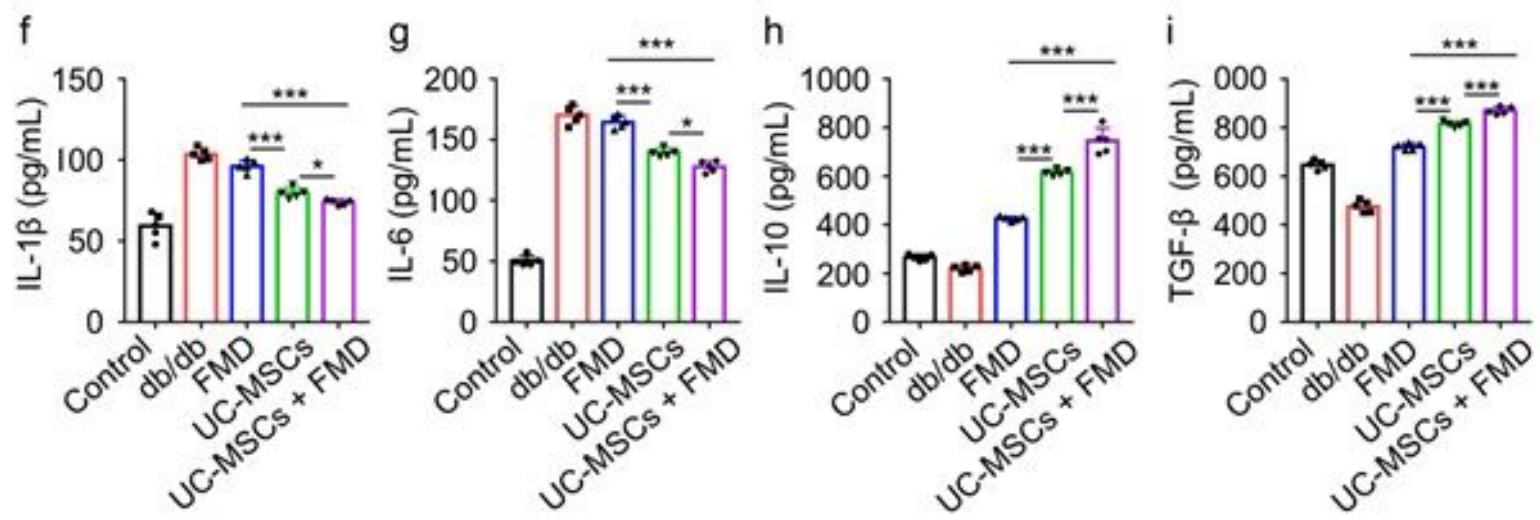

\section{Figure 7}

UC-MSCs combined with FMD regulated lipid metabolism in $\mathrm{db} / \mathrm{db}$ mice. (a): Liver steatosis were analyzed through staining with H\&E (Scale bar, $100 \mu \mathrm{m}$ ) and Oil Red O (Scale bar, $200 \mu \mathrm{m}$ ). (b): H\&E staining of Skin (Scale bar, $1 \mathrm{~mm}$ ) and Visceral fat (Scale bar, $100 \mu \mathrm{m}$ ). (c): The quantification of lipid accumulation in (a). (d): Thickness of subcutaneous fat layer quantification in (b). (e): Visceral adipocytes size quantification in (b). (f-i): The levels of serum IL-1 $\beta$, IL-6, IL-10 and TGF- $\beta$ were detected 
by ELISA. The data are expressed as mean values \pm SD. $n=6$ mice per group. ${ }^{*} P<0.05,{ }^{\star *} P<0.01, \star \star \star * P<$ 0.001 .

\section{Supplementary Files}

This is a list of supplementary files associated with this preprint. Click to download.

- GlycemicControlbyUCMSCsPromotesEffectsofFMDonT2D.pdf

- SupplementaryData.pdf 